\title{
Reviews on Plants Gum and Mucilage I: The Composition and Pharmacological Significance of Turmeric (Curcuma longa) Rhizomes Polysaccharides and Mucilage/their Aqueous Extracts Commercial Products
}

\author{
Hussein A. H AlSaidy \\ Department of environment and \\ polution-Marshes research center \\ University of Thi-Qar \\ Thi-Qar, Iraq \\ hussein-a-h@utq.edu.iq
}

\author{
Dhurgham A.H. Alhasan \\ Department of microbiology-college of \\ veternary medicine \\ University of Thi-Qar \\ Thi-Qar, Iraq \\ dhurghamalhasan@utq.edu.iq
}

\author{
Ali A. Ali \\ Department of marshes development- \\ Marshes research center \\ University of Thi-Qar \\ Thi-Qar, Iraq
}

https://doi.org/10.32792/utq/utjsci/v8/1/3

\begin{abstract}
The utilization of plants' polysaccharide as hydrocolloid materials within the last four decades, had drawn a significant attention due to their therapeutic and pharmaceutical applications. Among the Zingiberaceae family of plants, Curcuma longa $L$. rhizomes polyphenolic product like curcuminoids, flavonoids, turmerones and other polyphenolics had gained extensive investigation efforts and reported intensively. Curcuma longa L. rhizomes polysaccharide type mucilage hasn't received considerable attention by academic authors and researchers. In this survey, we tried to highlight this type of phytomolecules through exploring the issued research articles focusing on their pharmacological importance. Reference books, Scopus, PubMed, Web of Science bibliographic databases and Google scholar scientific search engines besides other open access researches sited on Google were screened for plant polysaccharides significances and uses in addition to their pharmacological activities. Screening was done using six different groups of keywords. All results found by keywords were reviewed and none-relevant articles were excluded by outcome of interests and researcher boundaries of study through a systematic method. It has been stated that, both mucilage and gums types of plants' polysaccharides had gained great investigation efforts in recent years. Concerning $C$. longa L. rhizomes; four different polysaccharides had been reported. They were to be isolated, purified and characterized from their polysaccharide mucilage aqueous extract then labelled as Ukonans $\mathrm{A}, \mathrm{B}, \mathrm{C}$ and $\mathrm{D}$. Several biological influences were studied for these polysaccharide compounds and mixtures as well as for their aqueous extracts fractions, including immune busting, anti-inflammatory, anti-ulcerogenic agent, insulin mimetic hypoglycemic agent, anticancer/chemopreventive and anti-obesity agent activities. Reviewed articles encouges us to conclude the potentiality of investigation of turmeric polysaccharides as pharmaceutical additive/and or co-therapy for several pathological conditions.
\end{abstract}

Keywords - turmeric, curcuma longa, polysaccharides, mucilage, pharmacological activities

\section{INTRODUCTION:}

Natural products for centuries had been in both medical as well as pharmaceutical fields. Nowadays; global attention is being paid to natural drugs and excipients. In recent years, plant-derived polymers especially hydro-colloidal substances like gums and mucilages have taken a tremendous attention via their various pharmaceutical uses. For example, as diluents, binders, and disintegrants as well as sustaining agents in tablets formulation in addition to act as protective colloids in suspensions, gelling agents in gels, oral liquids thickners, and bases in suppositories as well as let alone in cosmetics [1-3]. Gums and mucilages are naturally occurr in various plant parts, which are fundamentally pursued as cheap and plentiful. As a natural excepients they are widely applied as for both ordineary and novel dosage forms formulations in addition to exhibiting potentially feasible biodegradable polymeric materials [4]. These polymeric substances are preferentially considered over the semisynthetic and synthetic excipients due to the lack of toxicity, low cost, abundance in nature, soothing effect and nonirritant quality [5-9].

Many studies had conducted in fields including food technology and pharmaceuticals using gums and mucilages as excipients. However, in the field of designing of novel pharmaceutical dosage forms, these excipients often fulfil multiple advantages such as modifying drug release,

Website: https://utjsci.utq.edu.iq/index.php/main, Email: utjsci@utq.edu.iq 
increasing of the stability and bioavailability of the drug, enhancing of patient acceptance and ensuring of the simplicity of product manufacturing. Hence, there is a good number of plant-based pharmaceutical excipients in the markets. In addition, their capacity to exert a broad range of effects is based on both their properties and molecular weight. Natural polymers had became a lead in most of studies performed in the field of drug delivery systems. Moreover, such polysaccharide type polymers can also be altered to fulfill the requirements of drug delivery systems in order to compete with the commercially available synthetic excipients [10-12].

\section{POLYSACCHARIDE-BASED GUMS AND MUCILAGES IN THE PLANT PARTS}

The high molecular weight polymeric carbohydrates type known as polysaccharides are constructed of various monosaccharaides are linked together through a glycosidic bond with the elimination of water molecules.

$$
\mathrm{n} \mathrm{C}_{6} \mathrm{H}_{12} \mathrm{O}_{6} \rightarrow\left(\mathrm{C}_{6} \mathrm{H}_{10} \mathrm{O}_{5}\right)_{\mathrm{n}}+(\mathrm{n}-1) \mathrm{H}_{2} \mathrm{O}
$$

However, both of structural and sugar composition differences of these macromolecules lie behind the wide spectrum of their physical and biochemical applications. A broad range of polysaccharides, like agar, alginate, chitin and pectin, can form a hydrogel in both cold and hot water producing viscous solutions, colloidal dispersions or gels. The great interest with these polysaccharides are attributed to their gelling property [13]. Mucilage, gums and glucans are abundantly available in nature in many higher plants. They are also polysaccharide type hydrocolloids but of a broad range physicochemical properties as well as of unclear biological functions. Generally, some authors had reported that foliar mucilages are possibly just secondary metabolites unknown role in plant [15]. While others were mentioned to have a role in frost tolerance, water transport, wound responses, plant host-pathogen interactions, and other functions. The abundance of sugar monomers hydroxyl groups in the polysaccharide structure of mucilages contribute to the elevated water-binding tendency that may explain their role in water retention in the plants [16]. Polysaccharides are made of O-glycosidically linked monosaccharide residues of various types that have several applications as they are known as Cinderella of biopolymers [17]. Fundamentally, polysaccharides are of linear backbone structure of general formula $\mathrm{Cx}(\mathrm{H} 2 \mathrm{O}) \mathrm{y}$ where $\mathrm{x}$ is usually a vast number that ranges between 200 and 2500 although they have various degrees of branching. However; their monomeric building units are consist of multiple types of hexose type monosaccharides, to be expressed by the chemical formula $(\mathrm{C} 6 \mathrm{H} 10 \mathrm{O} 5) \mathrm{n}$ where $40 \leqslant \mathrm{n} \leqslant 3000$. There are various natural resources of polysaccharides including algal origin, plant origin, microbial origin and animal origin [18-19].

The vast majority of the natural polymer (gum and mucilage) are biodegradable, biocompatible and nonhazardous polymers showing irregular physical-chemical properties and environmentally sustainable features [13]. Never the less, despite the difference in the production source and water solubility of gums and mucilages, they have some similarities as being plant hydrocolloids, translucent amorphous substances, insoluble in organic solvents such as alcohol, acetone, ether and other nonpolar organic solvents, in addition to containing hydrophilic moieties that when interact with water form viscous solutions or gels. Chemically these polysaccharides upon hydrolysis, yield various monosaccharaides like arabinose, galactose, mannose and glucuronic acid [20]. Gums can be altered to modify their physicochemical properties. For example, gums can be modified through functional groups derivation, grafting with polymers, cross-linking with ions and other approaches. The factors influencing these processes that make them suitable for altering a drug release properties and other purposes have been thoroughly investigated by researchers concerning optimization of their performance [21].

\subsection{Classification of natural gum and mucilage}

Gums are available in huge amount in some plants parts, animals parts, sea weeds and fungi as well as other microbial origions. They have different chemical and metabolic activities. Plants represent the richest source of gums and mucilages. Gums and mucilages an be classified according to their sources, their shapes, their charge and the monomeric units present in chemical structure. Their sources include animal source like chitosan, chitin and chondroitin sulphate, marine source; like Agar, alginic acid and laminarin, microbial source ( bacterial as well as fungal sources): like Xanthan and dextran in addition to plant sources; like shrubs or tree exudates (such as gum Arabica, gum ghatti... etc.), seed gums (such as guar gum, locurt gum.... etc.), extracts (such as pectin, larch gum .... etc.) as well as from tuber and roots (such as potato starch ....etc.). according to their shapes gums and mucilages are classified into linear polysaccharides such as amylose, cellulose and pectin while branched polysaccharides including short branch (such as Xylan and xanthan) as well as branch on a branch type (such as amylopectin and gum Arabic). According to their charge they are classified into non-ionic polysaccharides; such as Guar gum, xanthan gum and dextrin, Anionic polysaccharides; such as Alginic acid, pectin and karaya gum, cationic polysaccharides; such as Chitosan, chitin and cationic guar gum, amphoteric polysaccharides: such as Carboxymethyl chitosan and NHydroxyldicarboxyethyl chitosan in addition to hydrophobic polysaccharides: such as Cetyl hydroxyethyl cellulose and polyquaternium. Finally, their classification according to the monomeric units present in chemical structure includes, homoglycans; such as amylose, arabinose and cellulose, diheteroglycans; such as algins, carrageenans, galactomannans, triheteroglycans, such as arabinoxylans, gellan gum and xanthan gum tetraheteroglycans: such as gum Arabic and psyllium seed gum in addition to pentaheteroglycans: such as gum ghatti and gum tragacanth [22].

\subsection{Biological activities of plants polysaccharides:}

Naturally occurring polysaccharides of different origins had long been studied and widely applied in various fields, such 
as in medicine and pharmaceutics. In the preceding and recent decades, polysaccharides from medicinal plants had attracted attention for investigation of their possible biological activities. They are interactive components of various medicinal plants aqueous extracts especially in the field of enhancement of host defense mechanisms. Several medicinal plants, like Angelica gigas, Phellinus linteus, Lentinus edodes, Schizophyllium commune, Platycodon grandiflorum isolated polysaccharides had been shown to possess immune stimulatory activity [23-25]. Furthermore, in multiple reported pre clinical and human clinical models; it was been found that orally administered polysaccharides and polysaccharide containing plant products have an immune modulatory effect. Besides, it had been reported that the that polysaccharides were found to be bioavailable in various in vivo and human clinical models after oral administration [26,27]. In this context, Curcuma zedoaria as well as Curcuma xanthorrhiza isolated polysaccharides had demonstrated to have macrophage-stimulating action via specific activation of NFk-B $[28,29]$.

Furthermore, as a water-soluble molecule as well as a primary cell wall structural composition of the plants' cells, pectin is classified as one of the highly complex and heterogeneous categories of polysaccharides. However, the majority of researches regarding pectin biological activity had related the reported effects to its side chain RG-I regions that contain galactan, arabinan and arabinogalactan [30]. plant-derived bioactive carbohydrate polymers such as pectic polysaccharides (PPs) have also been shown to exert multi-mechanistic gastro-protective effects [31,32]. Moreover, other various pharmacological activities, such as antiviral activity, antioxidant activity, antitumor activity, radio-protective effect, hepato-protective effect, and antifatigue effect are also attributed to polysaccharide part of plants extracts [33-36]. In this context, it was found that ginseng polysaccharide made of $1 \rightarrow 4$ linked homogalacturonan have anti-retrovirus activity [37]. Plant origin polysaccharides are believed to be effective in stimulating human immune systems, inhibiting viral replication, scavenging free radicals, and inhibiting lipid oxidation while they are in their native form [38-40].

\section{CURCUMA LONGA RHIZOMES PHYTOCHEMICALS}

Curcuma longa (C. longa) Linn. commonly known as turmeric, is a Zingiberaceae family perennial plant. Several health supplements in Asia, containing Curcuma longa extract as a common ingredient are used in various therapeutic applications such as blood purifying, wound healing, urinary tract infection, liver ailments and inflammatory disorders and holds a prominent position in traditional Indian medicinal system [41-43]. In modern pharmacological studies, the active components of $\mathrm{C}$. longa such as curcuminoids (a mixture of curcumin, demethoxycurcumin, and bisdemethoxycurcumin) the vital active constituents of C. longa, terminoids and sesquiterpenoids had been reported to possess multi-array biological activities such as anti-inflammatory, antioxidant, and chemo-preventive properties [44-47]. The different cellular components of immune system proliferation and cellular response was modulated by curcuminoids such as $\mathrm{T}$ cells, B cells, macrophages, neutrophils, natural killer NK cells and dendritic cells [48-50]. Besides, the epidemiological, preclinical and clinical data place turmeric within the most promising ingredients against cancer and chronic degenerative conditions, extending the healthy life span of humans [51,52]. Also, several works of the literature showed that turmeric has a hypoglycemic effect in experimental animal studies [53] through reducing glucose influx through the polyol pathway $[53,54]$ beside combating diabetes retino and nephropathy complication [55]. Recently, the release of the pro-inflammatory factor from adipose tissue known as leptin was found to be reduced or not affected by curcuminoids in clinical trials [56,57]. Furthermore, multiple animals as well as in vitro studies had reported the antimutagenic properties of curcumin, including activity against colon, skin, and breast cancer cells [58-63]. Also, it was reported that curcumin had inhibited the development of liver cirrhosis [64]. However, in HepG2.2.15 cells, it was suggested that C. longa L. extract can inhibit the HBV replication as well as HBV genes transcription, which produce $\mathrm{HBV}$ particles, and elevated the transcription level of the endogenous antitumor p53 gene [65].

\subsection{Isolation and the chemical structure of turmeric rhizomes polysaccharides}

Several methods have been reported to extract C. longa rhizomes polysaccharides, however; they vary in their steps constituents, procedure and the obtained fraction of polysaccharide. Besides, the extracted polysaccharides varied in polarity, structure and pharmacological activities. Lau et al. (2010) had extracted C. longa rhizomes polysaccharides into four fractions $\mathrm{H} 1-\mathrm{H} 4$ that are of different polarity and biological activities [66]. Rajagopal et al. (2018) and Dharmesh (2016), both had described the pectic polysaccharide (PP) isolation and purification from turmeric to be used as antiulcer agent through anti-inflammatory mechanisms mediated by anti-secretary, muco-protective and IL-10. However; the modified pectic polysaccharide was designated as (MTrPP) [67,68].

Moreover, Mohankumar and McFarlane (2011) had extracted C. longa powder for investigation of its antidiabetic activity [69]. Furthermore, Chinampudur et al. (2013) had described the extraction of polysaccharide fractions of $\mathrm{C}$. longa $F_{1}$ fraction for its immune-stimulatory and anti-inflammatory activities [70]. Furthermore, Tomoda et al. (1992) had reported a method for isolation of C. longa polysaccharides that give rise $22.6 \%$ (w/w) polysaccharides content. The resulted polysaccharides was fractionated through several steps to isolate a fourth neutral polysaccharide known as ukonan $\mathrm{D}$ beside the three known acidic polysaccharides of turmeric ukonans $\mathrm{A}, \mathrm{B}$ and $\mathrm{C}$. through gel chromatography using Sephadex-G-25 and DEAE-Sephadex-A-25 and various elution systems [71]. Earlier, Tomoda et al. (1990) had applied a similar method for the isolation of the three acidic polysaccharide known as ukonan $\mathrm{A}, \mathrm{B}$ and $\mathrm{C}$ where the polysaccharide total extract was $23.53 \%(\mathrm{w} / \mathrm{w})$ [72].

Shimizu N. et. al (1990) had isolated three of the four acidic ukonans namely ukonan A, B and C through electrophoresis and gel chromatography. They had uncovered the sugar units 
chemical composition of Ukonans A, B and C where Ukonan A. They was found that Ukonan A is composed of Larabinose, D-xylose, D-galactose, D-glucose, L-rhamnose and D-glucuronic acid in molar ratios of (12:4:12:1:4:10). While, Ukonans B and C are composed of the same sugar residues but of different molar ratio of $(12: 4: 12: 1: 2: 4)$ and (8:3:6:14:2:3) respectively [72]. However, (Tomoda M., et. al, (1990) had elucidated the sugar constituents of the glucan core of Ukonan A through both chemical as well as spectroscopic methods. They showed that the glycan core was made of a polysaccharide $(92.7 \%)$ and a peptide part (7.3\%). The polysaccharide part is made of an $\alpha$-L-arabino$\beta 3,6$-branched D-galactan and $\alpha-2,4$-branched L-rhamno- $\alpha-$ 1,4-linked D-galacturonan types skeleton. The last galacturanon fraction is of $\alpha-1,3$-joined L-arabinopyranose, $\beta$-3,4-branched D-xylose, $\alpha-1,4$-linked D-glucose, $\alpha-2,4-$ branched L-rhamnose and $\alpha-1,4-$ linked D-galacturonic acid residues [73]. However, Ukonan $B$ has the same sugar residue chemical composition of Ukonan A but of different molar ratios $[72,73]$ while, Ukonan $C$ has five additional type of sugar units in addition to that present in types $\mathrm{A}$ and $\mathrm{B}$. Later on, Ukonan A backbone had been elucidated using controlled Simth degradation approach and reported to be composed of $\beta$-1,3-linked D-galactose, $\beta$-1,4-linked $D$ xylose and $\alpha-1,2$-linked L-rhamnose residues. In addition, all of the galactose units in the core structure were joined at their 6 position with either of $\alpha$-L-arabino- $\beta$-D-galactosyl or $\beta$-D-galactosyl side chain [74].

Furthermore, Tomoda et al. (1993) had demonstrated that among the four forementioned polysaccharides Ukonan $\mathrm{C}$ was characteristically rich $(40 \%)$ in glucose residue. Its arabinogalactan backbone was found to be composed of 19 different type of sugar type residues these were; $\alpha$-Larabinose, $\alpha-1,3$-linked L-arabinose, $\alpha-1,5-$ linked Larabinose, $\alpha-2,5$-branched L-arabinose, $\beta-1,4-$ linked $\mathrm{D}$ xylose, $\beta$-3,4-brached D-xyloese, terminal $\beta$-D-galactose, $\beta$ 1,3-linked $\mathrm{D}$-galactose, $\beta$-1,4-linked $\mathrm{D}$-galactose, $\beta$-1,6linked D-galactose, $\beta$-2,4-branched D-galactose, $\beta,-3,6$ branched D-galactose, terminal $\alpha$-D-glucose, $\alpha-1,4$-linked Dglucose, $\alpha$-4,6-branched D-glucose, terminal $\alpha$-L-rhamnose, $\alpha$-1,2-linked L-rhamnose, $\alpha$-2,4-branched L-rhamnose and $\alpha$ 1,4-Iinked D-galacturonic acid residues. In addition, using controlled Smith degradation method, the arabinogalactane core structure of Ukonan $\mathrm{C}$ had been found to be formed of a backbone chain that is made of $\beta$-1,3-linked D-galactose and $\beta$-1,4-linked D-xylose. All of the galactose units in this backbone were found to be joined to a $\beta-1,6$-linked $D$ galactosyl side chains with or without terminal $\alpha$-L-arabinose units at position 3 [75].

Moreover, regarding Ukonan D it had been revealed that this C. longa polysaccharide had a molecular weight of 28000 and its core structure was made of L-arabinose, D-galactose, D-glucose and D-mannose type sugar residues at molar ratio of 1:1:12:0.2 respectively. In addition, these units were joined together in its glycan backbone in form of $\alpha-1,5$ linked L-arabino- $\beta-3,6$-branched D-galactan and $\alpha-4,6-$ branched D-glucan types structural fractions on one hand. On the other hand, unlike the acidic Ukanon C; the neutral Ukonan D was of smaller structure and had 10 types of sugars as compared to the 19 types sugar Ukonan C. However, Unkonan D had neither xylose nor rhamnogalactouronan fractions but it had remarkable terminal mannosyl units. Furthermore, it had found that
Ukonan D had greater content of glucose sugar residue than ukonan C [71].

\subsection{Biological activities of C. longa rhizomes polysaccharides}

Curcuma longa consists of carbohydrates $(69.4 \%$ of total mass), curcuminoids (curcumin, demethoxycurcumin and bisdemethoxycurcumin), and essential oil [76]. Of the carbohydrates part, pectin and glycan type polysaccharides were found to have a significantly diverse biological activities. Pectin and other polysaccharides can interplay with cell signalling and molecular mechanisms hence, they may have vital therapeutic implications. Pectins as a watersoluble polysaccharides, it is a principal structural feature of the plant cell wall. Besides, it is one of the most complex and heterogeneous classes of polysaccharides. However, the vast majority of research had attributed its observed various biological activities to the side chains RG-I regions composed of galactan, arabinan and arabinogalactan. Pectin molecules as charged substances have the property of mucoadhesion due to which they be can adsorb and crosslinked with mucin at the surface and interfacial layers of the gastric mucusa, resulting in a pectin-mucin stable coat. However, unlike the intact pectin structures of weak adhesive properties, the structurally modified pectin of stable adhesive properties exerts a potent muco-protective activity [77]. The turmeric roots water extracts that contain Ukonan A, Ukonan B, Ukonan C and Ukonan D polysaccharides were known to activate the reticuloendothelial system (RES) and the phagocytic activity in vitro [78]. In addition, polysaccharides containing $\mathrm{C}$. longa extracts had observed to have multiple biological activities like anti-tumour, anti depressant, anti oxidant, anti microbial, anti fertility, immune modulatory, and hepatoprotective properties [79-85] beside the potent antimetastatic activity of the biologically active pectic polysaccharide isolated from turmeric [86].

\subsubsection{Anti-inflammatory and immune-stimulatory activities of C. longa rhizomes polysaccharides}

The three closely related acidic polysaccharide fractions Ukonans $\mathrm{A}, \mathrm{B}$ and $\mathrm{C}$ were isolated and purified through multiple occlusion chromatographic steps from the total polysaccharide extract of the rhizomes of C. longa L. They were found to have a remarkably immune stimulating activity on reticuloendothelial system which was much more phagocytes activating effect than zymosan at concentration of $5 \mathrm{mg} / \mathrm{Kg}$ [72]. Later on, Ukonan D isolated by Tomoda et al. (1992) had shown a potent immune stimulating activity on the reticuloendothelial system at the same concentration [71]. Furthermore, Tomoda et al. (1992) had found that the acidic polysaccharide fraction of turmeric rhizomes known as Ukonan A and its degradation products shown a potent immune-stimulatory activity on the reticuloendothelial system cells phagocytes and lymphocytes at low concentration through three kinds of events; reticuloendothelial system potentiation, anticomplementary and alkaline phosphatase induction [74]. 
Interestingly, the structural study of the acidic polysaccharide Ukonan $\mathrm{C}$ had revealed well-known phagocytes-activating influence, considerably pronounced effect on reticuloendothelial system-potentiating and alkaline-phosphatase inducing activities. In addition, its arabinogalactan GALA core structure is of a pronounced impact on its anticomplementary activity [75].

Animal study of the Ukonan contenting polysaccharide fraction (F1) of turmeric roots aqueous extract (NR-INF-02) safety had showed LD50 >5 g/kg body weight for its oral tolerability indicating good safety. However, this fraction of NR-INF-02 had exhibited a significantly potential antiinflammatory effect in both acute and chronic inflammation models at dose range $11.25-45 \mathrm{mg} / \mathrm{kg}$ of body weight. The chronic and acute inflammation attenuation effect in rodent models might be related to the bioactive turmerosaccharides, arabinogalactans and Ukonans components of the polysaccharide F1 fraction of NR-INF-02. Hence, it could be emphasized as an importantly safe adjuvant product for management of osteoarriyhtitis [87]. Similarly, in an in vitro study implemented using human peripheral blood mononuclear cells (PBMC), the bioactive polysaccharide rich fractions especially $\mathrm{H} 2$ [88] isolated from the hot water extract of turmeric rhizomes had been found to cause significant stimulation of the PBMC proliferation especially CD14 count increase. In addition, fraction F2 remarkably elevated cytokines like (TGF- $\beta$, TNF- $\alpha$, GM-CSF, IL- $1 \alpha$, IL-5, IL-6, IL-8, IL-10 and IL-13, etc.) release without significant cytotoxicity at concentration range of $800 \mu \mathrm{g} / \mathrm{ml}$. These types of cytokines are involved in B cells proliferation and activation as well as $\mathrm{T}$ cell growth leading to an immune-modulatory effect. However; this multiple targets stimulating abilities indicates the potential use of whole C. longa crude extract (containing curcuminoids, turmerones and polysaccharides) as an adjuvant therapy supplement for immune compromised cancer patients due to chemotherapies [88].

Moreover, in a second in vitro study on murine splenocytes and macrophages, the fractionated NR INF 02 aqueous extract of turmeric rhizomes especially the polysaccharide rich fraction (F1) containing $12.6 \%$ polysaccharide and mother liquor (F2) had been found to have an immune modulatory activities. This immune modulatory influence was thought to occur through affecting the production of $\mathrm{T}$ cell cytokines including Th1 cells cytokines like (IL 2 and IFN $\gamma$ ) and Th2 cells cytokines like (IL 10) in a manner indicating its dual immune-stimulating and antiiflammatory functions. Polysaccharide fraction (F1) had been found to has much potent inhibitory effect than both NR INF 02 and fraction (F2). The polysaccharides rich fraction (F1) has twenty folds much potent inhibitory effect than NR INF 02 on PGE2 and IL 12 in LPS treated splenocytes besides its much powerful anti-inflammatory activity than F2 fraction exerted via the potent down regulation on the lipopolysaccharides LPS induced IL 12 and PGE2 release in mouse splenocytes and macrophages in vitro. Never the less, the two fractions of NR INF 02 in vitro immune stimulatory and cell proliferative influences could be attributed to its significant stimulation of nitric oxide NO, IL 2, IL 6, IL 10, IL 12, IFN $\gamma$, TNF $\gamma$ and MCP 1 synthesis and release in a concentration independent manner. NR INF 02 had exerted a powerful inhibitory activity on LPS stimulated IL 12 and
PGE2 production and release by the macrophages hence explained its observed anti inflammatory activity on one hand. On the other hand, the same mechanism explained its second potent immune stimulatory effect expressed by mean of macrophage activation, splenocytes proliferation and cytokine release. However, the polysaccharide rich fraction (F1) was twice as potent as NR INF 02 and almost ten times as potent as F2 as immune-stimulating remedy and had proposed that the polysaccharides have a contribution in its anti inflammatory and immune stimulatory activities [70]. Yegnarayan et al., 1976 in vivo study had shown that aqueous extract of $\mathrm{C}$. longa had potent as well as superior anti inflammatory activity than curcuminoids containing $\mathrm{C}$. longa extract [89].

In a third study, a commercialized formula of Curcuma longa (L) roots water extract marketed with the trade name (Turmeric Immune ${ }^{\mathrm{TM}}$ ) standardized for at least $20 \%$ of turmeric polysaccharides ukonan A, B, C and D had been reported to induce nitric oxide (NO) production in macrophages type RAW264.7. This influence may suggest the immune-modulatory effects of these ukonan family of polysaccharides. In addition, in an equivalence to curcumin, C. longa Linn polysaccharides had been reported to have a telomerase reverse transcriptase (TERT) activity upregulating effect. Therefore, it had been suspected that these polysaccharides might assist in promoting cellular immune responses and wounds repair by enhancing immune response and telomere function [90]. Recently, a fourth in vitro animal study conducted by Chandrasekaran et al. (2015) had studied the toxicity profile as well as the antiinflammatory activities of the first fraction (F1) polysaccharide of Curcuma longa aqueous extract (containing water extracts of Curcuma longa standardized to contain polysaccharides $>10 \% \mathrm{w} / \mathrm{w}$ ) evaluated in classical inflammation rodent models. Safety investigation in the study had revealed that NR-INF-02 was nontoxic up to 5000 $\mathrm{mg} / \mathrm{kg}$ body weight. However, the F1 fraction antiinflammatory activity was found due to its significant attenuation of acute and chronic inflammation. Hence, it was apparent that F1 polysaccharide fraction was bioavailable, safe and had activity against inflammation. In addition, its potent anti-inflammatory activity might be attributed to the arabinogalactans/ukonans components of the extract [91].

In other study, bioactive turmerosaccharides of NR-INF-02 were reported to be the major phytochemicals contributing to the observed anti arthritic effect in albino Wistar male rats knees when administered as 45 and $90 \mathrm{mg} / \mathrm{kg}$ single oral doses. There was no significant difference between tramadol the reference ant-iiflammatory drug treatment and turmerosaccharides rich fraction $(90 \mathrm{mg} / \mathrm{kg})$ on osteoarthritis pain. Despite, both fractions of turmerosaccharides produces significant analgesic effect, however the observed influence of the turmerosaccharides rich fraction of the product $(57 \%)$ in attenuation of osteoarthritis pain was superior to that of the turmeric polysaccharides less fraction (35\%) [92]. Hence, the less fraction showed significant analgesic effect, which was inferior to turmeric polysaccharides rich fraction. This indicates that turmerosaccharides less fractions might have other bioactive phytochemicals that were responsible for its analgesic effect. 
Actually, turmeric polar extract had been numerously reported to be used for joint healing effect antiinflammatory activity and knee pain reduction in osteoarthritis. Evaluation of turmacin TM on cartilage homeostasis in human articular chondrocytes knee (NHAC$\mathrm{kn}$ cells) had revealed that it protects cartilage homeostasis through keeping an equivalence between the production and destruction of cartilage matrix. The probable biochemical mode of action might be via several pathways. First, through reduction of the chondrocytes degradation factors like IL$1 \beta$-induced cytotoxicity death and apoptosis in a concentration dependent profile respectively. Second, reduction of $\mathrm{H} 2 \mathrm{O} 2$-induced senescence and significantly inhibits the release of degradation catabolic factors such as the pro-inflammatory interleukin mediators IL-6, IL-8, inflammatory signaling molecules as well as eicosanoids like COX-2, PGE2, TNF- $\alpha$.

Third, through suppressing the expression of LPS-induced NF-kB as well as ICAM-1 that stimulate cartilage degrading enzymes. All of these pathways are related to osteoarthritis symptoms such as pain and joints function disabilities. On other side, NR-INF-02 preserves the synthesis machinery of building biomolecules like glycosaminoglycans and collagen type II. However, as chondrocytes apoptosis is potentially significant in cartilage degeneration besides it could has a reasonable depressing effect on chondrocyte senescence via inhibiting oxidative stress of hydrogen peroxide, NR-INF-02 inhibitory effects on apoptosis lies behind its cartilage protecting action as it has no proliferation influence on NHAC-kn cells [93].

In an in vivo randomize clinical a study using curcuminoids free polysaccharides rich polar water extract of turmeric rhizomes NR-INF 02 (turmacin TM), had shown clinical acceptable safety, efficacy and tolerability in a randomized placebo controlled study on a small group 120 human patients (37 males and 83 females) affected with primary osteoarthritis with primary painful knee. The polar polysaccharide components in this herbal product were considered as the primary effective component for curing osteoarthritis including pain relief, reduction in joint tenderness and effusion. Thereby this polysaccharide rich herbal product causes an enhancement in joint function of affected especially these with 2nd and 3rd degree osteoarthritis for patients having more than 6 months pain when given in a dose of $500 \mathrm{mg}$ capsule twice daily. The proposed mode of actions of Curcuma longa Linn. aqueous extracts involved in the improving of signs and symptoms of osteoarthritis was attributed primarily to their antiinflammatory and anti-oxidant characteristics mediated through several biochemical factors like eicosanoids, cytokines and other pro-inflammatory factors as formerly discussed. Interestingly, its onset of beneficial effect, was observed within 1 month that might be awed to the polysaccharides physicochemical properties contributing to the enhanced potency and therefore its pharmacological effect [94]. Never the less, despite that both of the preferable pharmacokinetic profiles of the joint health ingredients glucosamine and chondroitin as well as lack of their efficacy on inducing repairing structural changes in joint cartilage $[95,96]$, the polysaccharide herbal product NR-INF-02 succeeded to induce such joint health beneficial changes within 21 days of its oral administration [94].
Remarkably, turmeric (C. longa) aqueous extracts had been reported to promote the adhesion of peripheral neutrophils to human umbilical vein endothelial cells by mean of stimulating the cell adhesion molecules expression, like the intercellular adhesion molecule-1 (ICAM-1), vascular cell adhesion molecule-1 (VCAM-1) and E-selectin. These biomediators permit the extravasation and migration of body's effector cells process to the site of immune activation. This immune cells extravasation and migration from blood vessels to the sites of injuries and/or infections is critical for immune response. Turmeric aqueous extract had exerted an enhancement of neutrophils adhesion to blood vessel endothelium in a concentration-dependent manner with maximum effect at $350 \mathrm{ng} / \mathrm{ml}$ and $700 \mathrm{ng} / \mathrm{ml}$ through causing up regulation of E-selectin and ICAM-1 expression respectively. The mechanism by which turmeric aqueous extract induced the cell adhesion molecules expression was found to be through activation of nuclear transcription factor NF-kB, a key biomolecule included in ICAM-1, VCAM-1 and E-selectin gene transcription events. Madan (2001) believed that $\mathrm{C}$. longa aqueous extract may activate any of the protein kinases $\mathrm{C}$ and protein tyrosine kinase [97,98].

\subsubsection{Anti-ulcer activity of turmeric peptic polysaccharides (TrPPs) and its chemically modified low molecular weight fragments MTrPP:}

The native, intact turmeric peptic polysaccharides (TrPP) PPs isolated from fresh turmeric with a yield of $6.3 \%$ as well as their modified low-molecular-weight forms pectic polysaccharides (MTrPPs) obtained by sequential alkaliacid treatment ( $\mathrm{pH}$-dependent chemical alteration) had been evaluated in both in in vitro as well as in vivo rat models for their potential ulcer-prevention effect. MTrPPs fragments of C. longa Linn containing homogalacturonan (HG), and rhamnogalacturonan $(\mathrm{RG}-\mathrm{I})$ rich domains in their galactan cores had exhibited a multi-dimensional ulcer-prevention effects. These effects involved inhibiting excessive acid secretion, gastric mucus layer integrity maintenance, modulation of antioxidant mechanisms besides inhibition of H. pylori growth and adherence. Investigation of the results had revealed that MTrPP had a significantly better ulcerprevention property; (up to $85 \%$ ulcer inhibiting effect) than intact TrPP, thus it is ( $\sim 2$ folds) more efficient than TrPP. Furthermore, MTrPPs had exhibited a very close protection rate up to $84 \%$ (at $200 \mathrm{mg} / \mathrm{kg} \mathrm{b.w}$ ) to that offered by lansoprazole $86 \%$ (at $50 \mathrm{mg} / \mathrm{kg} \mathrm{b.w}$ ) on one hand. On the other hand; TrPP had shown only up to $49 \%$ protection rate at the same dose. MTrPPs anti-ulcerogenic activity was attributed to their effective muco-protection, $\mathrm{H}+, \mathrm{K}+-$ ATPase down-regulation, inhibition of $H$. pylori growth/adherence as well as higher antioxidant/cytoprotective mechanisms [68]. Structural data had revealed that TrPP varies from MTrPP in molecular weight, sugar compositions as well as side chain monosaccharide monomer types ratios. However, unlike TrPP that have no inhibitory effect noticed on $\mathrm{H}$. pylori, MTrPP had exhibited an anti-H. Pylori activity with an IC50 value of $44 \mu \mathrm{g} / \mathrm{ml}$, which was comparable to that of amoxicillin $(26 \mu \mathrm{g} / \mathrm{mL})$. MTrPP pre-dominantly inhibited $\mathrm{H}$. pylori-mediated HA showing anti-H. Pylori mucoadhesive property with an IC50 of $36 \pm 3.3 \mu \mathrm{g} / \mathrm{ml}$. 
This muco-adhesion counteracting activity was attributed to the fact that TrPP as a whole molecule might have problems in penetrating microbial cells, hence, the smaller size of modified pectins (MTrPP) significantly contributes to their biological activity execution. Consequently, from the structural perspectives; the relatively higher degree of GalA content in MTrPP with loss of some neutral side chains due to modification explains their better antimuco-adhesive property [99].

Furthermore, TrPPs were able to maintain the reduction of mucin-like glycoproteins in rats during ulceration through mucin content up-regulation nearly up to three folds. This effect exhibited a significant role in gastric mucin protective layer re-establishment associated with the ulcer-prevention properties of C. longa PPs. One of turmeric PPs gastroprotective probable mechanism is to interact with mucin, which subsequently produces a complex gel lining as a barrier over the stomach mucosa to protect it against ulcerinducing agents. The mucoadhesive properties rhamnogalacturonan part of their pectin part can protect the gastrointestinal wall from damage that's why MTrPP had shown considerably higher muco-protective properties as compared to TrPP. Moreover, despite albeit TrPPs possessed higher phenolic content than MTrPP (as experimental data revealed), MTrPP antioxidant properties weren't largely driven by phenolics in MTrPPs due their high GalA content. GalA is a well-known potent scavenger of free radicals. Therefore, pectin's minimal structural features are critical for possessing its therapeutic effects against gastric ulcer. Primarily homogalacturonan and galactan rich RG-I region of MTrPP, had been found to be responsible for its anti-ulcer activities. hence, the superior MTrPP ulcer preventive property was attributed to two factors; first MTrPP rich contents of homogalacturonan and rhamnogalacturonan-I that were composed of galactans that may decrease ulcerations due to inflammatory processes. Second, the lower molecular weight of MTrPP (13 kDa) possibly increased MTrPPs absorption so may increase their bioavailability as compared to $\operatorname{TrPP}$ (about $150 \mathrm{kDa}$ ) [68].

Later on, the antiulcer potency and inhibitory effects on Helicobacter pylori of the structurally defined low molecular weight (MTrPPs) had been shown to be up to $91 \%$. Their gastric protection activity was thought to be through this polysaccharides capability to limit the production of pro-inflammatory factors $(\mathrm{TNF}-\alpha, \mathrm{IL}-8, \mathrm{NF}-$ $\kappa \mathrm{B})$ in addition to their tight differential regulation of cyclooxygenase (COX-1, 2). MTrPPs cause inhibition/down-regulation of COX-2 more selectively, while up-regulating $\mathrm{COX}-1$ enzyme, mitogen-activatedprotein-kinase $(\mathrm{p}-\mathrm{p} 38, \quad \mathrm{p}-\mathrm{ERK}-1 / 2)$ and matrix metalloproteinase (pro-MMP-9). However, at the molecular level the inhibition of galectin-3, oxidative stress, $\mathrm{H}+, \mathrm{K}+-$ ATPase as well as of gastroprotective mediators such as mucin, prostaglandin E2, NO, zinc, IgA etc. lies behind MTrPPs inflammation modulatory effects. Thus, the overall muco-protective effect of MTrPPs was mediated by creating suitable gastric mucosa protection environment through switching from the inflammatory to the anti-inflammatory phase via IL-10 overexpression in addition to mucoprotective and anti-secretary properties beside its antioxidant and immune-boosting potential [67].

\subsubsection{Insulin-mimetic and anti-obesity activities of $C$. longa rhizomes polysaccharides:}

Aqueous extract of Curcuma longa (AEC) hypoglycemic effect was attributed to its influence on glucose homeostasis. It had been found to stimulate insulin secretion at both basal and hyperglycemic conditions from the pancreatic tissues. However; its optimum effect was merely $68 \%$ of tolbutamide; an oral hypoglycemic agent. AEC alone had been found to cause a gradual-steps glucose uptake stimulation from the abdominal muscle tissues in the absence as well as the presence of insulin, besides in case of AEC and insulin combination. This finding had significantly potentiated the hypothesis that glucose was up taken into abdominal muscle tissue via the insulin-mediated glucose uptake pathway, which may be very similar to the effect of metformin. Therefore; it was proposed that water-soluble compounds of turmeric exhibit insulin releasing and mimicking actions within in vitro tissue cultures [69].

Never the less, the influence of turmeric rhizomes aqueous (50\% hydro-alcoholic) extract on leptin release from the human subcutaneous adipose tissue (SAT) in overweight diabetic patients had also been studied. C. longa aqueous extract at 0.1 and $1 \mathrm{mg} / \mathrm{ml}$ doses treatment of SAT in both male and female patients had inhibited the release of leptin, while two days of SAT treatment with only $1 \mathrm{mg} / \mathrm{ml}$ dose of C. longa polar extract had inhibited leptin release in a manner comparable to the anti-inflammatory results of the low bioavailable curcuminoids. This study had shed light on the role of leptin and adipose tissue in the $C$. longa mechanism of reducing low-grade inflammation. Hence, it was proposed that on long term use, Curcuma longa aqueous extract may minimize leptin resistance and its related chronic diseases [99].

\subsubsection{Anticancer/chemopreventive effects and safety of $C$. longa rhizome polysaccharide rich aqueous extracts at the genetic level:}

In an in vitro study the oral safety in addition to the possible genotoxic potential (mutagenic and/or the carcinogenic) on bacteria, mammalian as well as human cells models of $\mathrm{C}$. longa rhizome polysaccharide rich aqueous extract, Turmacin TM or NR-INF-02 were performed. The study had revealed that there were neither mutagenic effect as well as cell toxicity nor mutagenic property observed in bacterial models at concentration up to $5 \mathrm{mg} / \mathrm{ml}$ nor cell toxicity/genotoxicity potentials were observed in mammalian as well as human cells models at a dose range up to $2.5 \mathrm{mg} / \mathrm{ml}$. In addition, good oral safety was observed after 2 weeks of single doses administered orally upto $5 \mathrm{gm} /$ $\mathrm{Kg}$ body weight [100] which is in accordance with the findings of (Shankar et al. 1980) [101]. Therefore, this study had confirmed that Turmacin TM polysaccharides might be genotoxically safe and non-mutagenic beside its remarkably significant oral safety at dose of $5 \mathrm{~g} / \mathrm{kg}$ rat body weight [100]. However, in another study, the investigation of the in vivo chemopreventive activity of the curcumin-free aqueous turmeric extract (CFATE) on 7,12Dimethylbenz[a]anthracene (DMBA) induced mammary tumorigenesis initiation and post-initiation phases in animal 
models had revealed that simultaneous 1\% CFATE solution administration as the only source of drinking throughout the initiation phase neither suppresses the tumorigenesis nor prevent its incidence. However, $48 \mathrm{hr}$ after DMBA treatment, administration of $1 \%$ CFATE as the only source of drinking and continuing throughout the post-initiation phase had led to a significantly suppressed tumorigenesis process. CFATE had caused a decline in the multiplicity of tumor cells by $43 \%$ and/or tumor impact however; tumor incidence was unaffected indicating its weak post-initiation phase activity. While, it was ineffective in suppressing tumor multiplicity, reducing tumor impact or preventing tumor incidence [77].

In a second in vivo study in animal models the effect of CFATE concentrations $0.2 \%, 1.0 \%, 5.0 \%$ during the initiation phase at $1 \mathrm{mg}$ orally administered dose (twice weekly for 4 weeks) as the only source of drinking on the benzo(a)pyrene $(\mathrm{B}(\mathrm{a}) \mathrm{P})$-induced papillomas had revealed a significant suppression on (B(a)P)-induced tumorigensis. This polysaccharides rich extract had brought about a decline in both tumor multiplicity to a minimum levels $8 \%$ $, 2 \%, 3 \%$ as well as the incidence of tumor to $54,86,80 \%$ with respective to the former concentrations. Never the less, CFATE effect as the only drinking source on the postinitiation phase had led to $\mathrm{B}(\mathrm{a}) \mathrm{P}$-induced multiple gastric tumors development inhibition with maximum antitumorigensis level at $5 \%$ CFATE concentration of the dose without affecting the tumor incidence. Furthermore, CFATE gastric tumor counteracting effect was greater during the initiation phase rather than the post-initiation phase. Also, in the initiation phase treatment with various concentrations of CFATE had elucidated no evident differences in its tumor multiplicity and tumor incidence suppression effect $>90 \%$ for all former concentrations. While, upon treatment using $5 \%$ concentration of CFATE is started before, with and after the starting of carcinogen administration (initiation phase) a complete prevention to the establishment of papillomas in mice forestomach was observed. In addition, oral treatment of all of the formerly mentioned CFATE concentrations through the initiation and post-initiation had never showed any gross changes in the final body weight, liver weight and liver to body weight ratios of the experimental animals or any sings of overt toxicity [102] to crude turmeric or its ethanolic extracts. The potent CFATE chemopreventive activity which is of 5 and 25 folds (i.e. at $1 \%$ and $0.2 \%$ concentrations) greater efficacy than the former study might be awed to the multiple active phytochemicals which are probably of different modes of action.

Finally, in an in vitro part of study to the aqueous turmeric extract (AqTE) and its curcumin free fraction (CFATE) remedies chemopreventive activity against chemical mutagenes and carcinogens both had a significant antimutagenic activity in bacterial strains of $S$. typhimurium, TA 98 and TA 100 against both direct-acting mutagens and indirect mutagens in animal model. While the in vivo investigation part, the mutagenicity of $\mathrm{B}(\mathrm{a}) \mathrm{P}$ induced liver and forestomach in animal models was significantly inhibited by both of AqTE and (CFATE). A protective $3 \mathrm{mg} / \mathrm{animal}$ dose of AqTE and (CFATE) $18 \mathrm{~h}$ before benzo[a]-pyrene administration had found to cause a significant inhibition of bone marrow micronuclei formation in mice females by $43 \%, 76 \%$ respectively. However, they cause a significant inhibition to the incidence and multiplicity of B-(a)P-induced forestomach tumours (decrease in the average number of papillomas/animal by $78 \%$ and $82 \%$ respectively) when the same dose is administered orally twice weekly for 4 weeks throughout the experiment (before, during and after mutagen administration). The probable mechanism of activity of the aqueous $\mathrm{C}$. longa extracts chemoprotective influence against $\mathrm{B}(\mathrm{a}) \mathrm{P}$-induced mutagenicity was believed to be through inhibiting the metabolizing enzymes mediating the mutagen carcinogenicity. The chemoprotective effects of the two polysaccharide rich aqueous turmeric extracts are dose dependent in both in vivo and in vitro parts of the study with an apparent protective influence against genomic damage caused by carcinogens and tumorigens [102].

\section{CONCLUSIONS AND RECOMMENDATIONS:}

Surveying literatures for the significances of C. longa Linn rhizomes reveals tremendous advantages and implications of the plant's polysaccharides, polysaccharide rich turmeric aqueous extracts and their commercial products. They act firstly as inducers of inflammatory and pro-inflammatory mediators like cytokines, ecosanides. Secondly, as up regulators of cell adhesion molecules and/or activators of NF-kB ...etc. indicating their immune busting, antiinflammatory activities. This immune modulatory activities nominate these polysaccahrides to be investigated for their use alone or in combination as an adjuvant topical treatment for topical skin and mucus membrane lesions like in cases of lepromatous leprosy, cancers and viral infections beside burns and wounds. However, despite the huge number of research articles concerning using plant hydrocolloidal polysaccharides gums and mucilage; no report have been found regarding the use of $\mathrm{C}$. longa Linn rhizomes as a pharmaceutical excipient for an ordinary or novel drug delivery dosage forms. As polymeric substances of hydrocolloidal system forming capability, C. longa rhizomes Ukonan type polysaccharides have a potential to explore their use as both carrier and therapeutic polymer in simulation to other polymeric anticancer polysaccharides like chitosan on one hand. Moreover, investigation of $\mathrm{C}$. longa L. rhizomes whole polysaccharides extract or its fractionated pure ukonans/ their derivatives physicochemical properties like swelling index, viscosity and gelling effect at various temperatures and different $\mathrm{pHs}$. Positive results may nominate them to be invested in anticancer drugs formulations as micellular anticancer cargo carrier or polymeric mutual produrg carrier uploaded with cytotoxic agents on one hand or to be used as pharmaceutical excipients for various possible dosage forms. On the other hand, their modified form gastroprotective influence encourages studying the use of these polysaccharides as anti-ulcer pharmaceutical dosage form in combination with the anti-hyperacidity compounds. Moreover, their anti-diabetic/anti-obesity effects may finds application in anti-obesity and anti-diabetic herbal formulations. Thus; we recommend first; to investigate the molecular mechanism by which $\mathrm{C}$. longa L. polysaccharides as pure ukonan fractions exert first their antidiabetic and/or anti-obesity activity in vivo especially on leptine receptors. 


\section{REFERENCES}

1. Zatz, J. L., Kushla, G. P., (1989), “In Pharmaceutical dosage forms-Disperse systems”, M. M. Reiger and G.S. Banker, Ed; Marcel Dekker Inc., New York, (1989) $2^{\text {nd }}$ edition, pp: 508.

2. Jania, G. K., Shahab, D. P., Prajapati, V. D., Jainb, V. C., (2009), Gums and mucilages: versatile excipients for pharmaceutical formulations, Asian J. Pharmaceutical Sci., 4(5) :309-323.

3. Deogade, U. M., Deshmukh, V. N., (2012), "Natural gums and mucilage' in NDDS: Applications and recent approaches", IJPTR, 4(2):799-814.

4. Goswami, S., Naik, S., (2014), "Natural gums and it's pharmaceutical application", Journal of Scientific and Innovative Research, 3(1) :112-121.

5. Whistler, R. L., (1996), In Industrial gums, $2^{\text {nd }}$ Ed., Academic Press, London.

6. Kakrani, H. K., Jain, N. K., (1981), A study on binding properties of guggal gum., Indian J. Hospital Pharmacist, XVIII(3) :100-102.

7. Bhunvara, N. S., Khorana, M. L., (1985), "Studies on suspending properties of Hyprophila spinosa", Indian Drugs, (22) :500-502.

8. Kulkarni, G. T., Gowthamarajan, K., Dhobe, R. R., Yohanan, F., Suresh, B., (2005), "Development of controlled release spheroids using natural polysaccharide as release modifier", Drug Deliv., (12) :201-206.

9. Deogade, U. M., Deshmukh, V. N., Sakarkar, D. M., (2012), "Natural Gums and Mucilage's in NDDS: Applications and Recent approaches" International Journal of Pharm Tech Research, 4(2) :799-814.

10. Bharat, W., Yogita, A., (2013), “Gums and Mucilages: Excipients for modified Drug Delivery", Journal of Advanced Pharmacy Education \& Research, 3(4) :359-367.

11. Banker, G. S, Anderson, N. R., (1987), Tablets., In Lachman L., Lieberman H. A., Kanig J. L., The theory and practice of industrial pharmacy., $3^{\text {rd }} \mathrm{Ed}$., Mumbai: Varghese Publishing House, :336.

12. Bhardwaj, T. R, Kanwar, M., Gupta, A., (2000), "Natural gums and modified natural gums as sustainedrelease carriers", Drug Dev Ind Pharm, (26) :1025-38.

13. Shah, S. N, Asghar, S., Choudhry, M. A., Akash, M. S., ur-Rehman N., et al., (2009), "Formulation and evaluation of natural gum-based sustained release matrix tablets of flurbiprofen using response surface methodology", Drug Dev. Ind. Pharm, (35) :1470-1478

14. Clifford, S. C., Arndt, S. K., Popp, M., Jones, H. G., (2002), "Mucilages and polysaccharides in Ziziphus, species (Rhamnaceae): localisation, composition and physiological roles during drought-stress", J. Experimental Botany, 53(366) :131-138.

15. Naglschmid, F., Kull, U., Jeremias, K., (1982), Physiologische Untersuchungen über Blattschleime. Untersuchungen an Verbascum densiflorum. Biochemie und Physiologie der Pflanzen, (177) :671685.
16. Clarke, A. E., Andreson, R. L., Stone, B. A., (1979), "Form and function of arabinogalactans and arabinogalactan-proteins", Phytochemistry, (18) :521540 .

17. Stephen, A. M., Churms, S. C., (2006), "Food polysaccharides and their applications", Taylor and Francies, CRC Press, New York, Edited by Stephen AM, Phillips GO and Williams PA, pp: 1-24.

18. Koleng, J. J., McGinty, J. W., Wiber, W. R., (2009), Handbook of pharmaceutical excipients. Pharmaceutical Press, $6^{\text {th }}$ Ed., Edited by Raymond C Rowe, Paul J Sheskey and Marian E Quinn, pp: 1-3.

19. Kottke, K. M., (2002), Modern Pharmaceutics., Marcel Dekker, New York, pp: 287-333.

20. Singh S., et al., (2010), Pharmaceutical characterisation of Cassia tora seed mucilage in tablet formulations., Scholar Research Library, 2(5) :54-61.

21. Rana, V., Rai, P., Tiwary, A. K., Singh, R. S., Kennedy, J. F., et al., (2011), "Modified gums: Approaches and applications in drug delivery", Carbohydrate Polymers, (83) :1031-1047.

22. Karmakar, K., (2016), "Application of Natural Gum as a binder in Modern Drug Delivery", J Anal Pharm Res, 3(4) :00061.

23. Wasser, S. P., (2002), "Medicinal mushrooms as a source of antitumor and immunomodulating polysaccharides", Appl Microbiol Biotechnol, (60) :258-74.

24. Jeon, Y. J., Kim, H. M., (2001), “Experimental evidences and signal transduction pathways involved in the activation of NF-kappa B/Rel by angelan in murine macrophages", Int Immunopharmacol, (1) :1331-9.

25. Yoon, Y. D., Kang, J. S., Han, S. B., Park, S. K, Lee, H. S, Kang, J. S., et al., (2004), Activation of mitogen-activated protein kinases and AP-1 by polysaccharide isolated from the radix of Platycodon grandiflorum in $R A W \quad 264.7$ cells., Int Immunopharmacol, (4) :1477-87.

26. Ramberg, J. E., Nelson, E. D., Sinnott, R. A., (1993), "Immuno-modulatory dietary polysaccharides: A systematic review of the literature", Nutr. J, (9) :54.

27. Trnovec, T., Hrmová, M., (1993), "Immunomodulator polysaccharides: Chemistry, disposition and metabolism", Biopharm Drug Dispos., (14) :187-98.

28. Kim, K. I., Shin, K. S., Jun, W. J., Hong B. S., Shin D. H., et al., (2001), "Effects of polysaccharides from rhizomes of Curcuma zedoaria on macrophage functions", Biosci Biotechnol Biochem., (65) :2369-77.

29. Kim, A. J., Kim, Y. O., Shim, J. S., Hwang, J. K., (2007), 'Immuno-stimulating activity of crude polysaccharide extract isolated from Curcuma xanthorrhiza Roxb.", Biosci Biotechnol Biochem., (71) :1428-38.

30. Ridley, B. L., O’Neill, M. A., \& Mohnen, D., (2001), "Pectins: Structure, biosynthesis, and oligogalacturonide-related signaling”, Phytochemistry, 57(6) : 929-967.

31. Srikanta, B. M., Sathisha, U. V., \& Dharmesh, S. M., (2010), "Alterations of matrix metalloproteinases, gastric mucin and prostaglandin $E$ (2) levels by pecticpolysaccharide of swallow root (Decalepis 
hamiltonii) during ulcer healing", Biochimie, 92(2) :194-203.

32. Srikanta, B., Siddaraju, M., \& Dharmesh, S., (2007), “A novel phenol-bound pecticpolysaccharide from Decalepis hamiltonii with multi-step ulcer preventiveactivity", World Journal of Gastroenterology: WJG, 13(39) :5196-5207.

33. Harlev, E.,Nevo, E., Lansky, E. P., Ofir, R., Bishayee, A., (2012), "Anticancer potential of aloes :Antioxidant, antiproliferative, and immune-stimulatory attributes", Planta Medica, 78(9) :843-852.

34. Jin, M., Huang, Q., Zhao, K., Shang, P., (2013), "Biological activities and potential health benefit effects of polysaccharides isolated from Lycium barbarum L.", International Journal of Biological Macromolecules, (54), :16-23.

35. Li, T., Peng, T., (2013), "Traditional Chinese herbal medicine as a source of molecules with antiviral activity", Antiviral Research, 97(1) :1-9.

36. Thakur, M., Weng, A., Fuchs H., Sharma V., Bhargava C. S., et al., (2012), "Rasayana properties of Ayurvedic herbs: Are polysaccharides a major contributor", Carbohydrate Polymers, 87(1) :3-15.

37. Tian, L., Zhao, Y., Guo, C., Yang, X., (2011), " $A$ comparative study on the antioxidant activities of an acidic polysaccharide and various solvent extracts derived from herbal Houttuynia cordata", Carbohydrate Polymers, 83(2) :537-544.

38. Baek, S. H., Lee, J. G., Park, S. Y., Bae, O. N., Kim, D. H., Park, J. H., (2010), "Pectic polysaccharides from Panax ginseng as the antirotavirus principals in ginseng", Biomacromolecules, 11(8) :2044-2052.

39. Harhaji-Trajkovic, L. M., Mijatovic, S. A., Maksimovic-Ivanic, D. D., et al., (2009), “Anticancer properties of Ganodermal ucidum methanol extracts in vitro and in vivo", Nutrition and Cancer, 61(5) :696-707.

40. Ke, M., Zhang, X.-J., Han, Z.-H., Yu, H.-Y., et al., (2011), "Extraction, purification of Lycium barbarum polysaccharides and bioactivity of purified fraction", Carbohydrate Polymers, 86(1) :136-141.

41. Khanna, N. M., (1999), “Turmeric, Nature's precious gift", Curr Sci, (76) :1351-6.

42. Dixit, V. P., Jain, P., Joshi, S. C., (1988), "Hypolipidaemic effects of Curcuma longa $L$ and Nardostachys jatamansi, DC in triton-induced hyperlipidaemic rats”, Indian J Physiol Pharmacol., (32) :299-304.

43. Luper, S., (1999), "A review of plants used in the treatment of liver disease part two", Altern Med Rev., (4) :178-188.

44. Singh, S., Aggarwal, B. B., (1995), "Activation of transcription factor NF-kappa $B$ is suppressed by curcumin (diferuloylmethane)”, J Biol Chem., (270) :24995-5000.

45. Plummer, S. M., Holloway, K. A., Manson, M. M., Munks, R. J., et al., (1999), "Inhibition of cyclo-oxygenase 2 expression in colon cells by the chemopreventive agent curcumin involves inhibition of NF-kappaB activation via the NIK/IKK signaling complex", Oncogene, (18) :6013-20.

46. Aggarwal, S., Ichikawa, H., Takada, Y., et al., (2006), "Curcumin (diferuloylmethane) down-regulates expression of cell proliferation and antiapoptotic and metastatic gene products through suppression of Ikappa Balpha kinase and Akt activation”, Mol Pharmacol., (69) :195-206.

47. He, X. G., Lin, L. Z., Lian, L. Z., Lindenmaier, M., (1998), "Liquid chromatography electrospray mass spectrometric analysis of curcuminoids and sesquiterpenoids in turmeric (Curcuma longa)", J Chromatogr, (818) :127-32.

48. Bhaumik, S., Jyothi, M. D., Khar, A., (2000), "Differential modulation of nitric oxide production by curcumin in host macrophages and NK cells", FEBS Lett, (483) :78-82.

49. Churchill, M., Chadburn, A., Bilinski, R. T., Bertagnolli, M. M., (2000), "Inhibition of intestinal tumors by curcumin is associated with changes in the intestinal immune cell profile.” J Surg Res, (89) :169-75.

50. Jagetia, G. C., Aggarwal, B. B., (2007), "Spicing up of the immune system by curcumin", J Clin Immunol, (27) :19-3

51. Pan, M. H., Lai, C. S., Ho, C. T., (2010), “Antiinfllammatory activity of natural dietary flavonoids", Food Funct., (1) :15-31.

52. Pan, M. H., Lai, C. S., Tsai, M. L., Wu, J. C., Ho, C. T., (2012), "Molecular mechanisms for anti-aging by natural dietary compounds”, Mol Nutr Food Res., (56) :88-115.

53. Suresh, B. P., Srinivasan, K., (1998), "Amelioration of renal lesions associated with diabetes by dietary curcumin in streptozotocin diabetic rats", Mol Cell Biochem, (181) : 87-96.

54. Arun, N., Nalini N., (2002), "Efficacy of turmeric on blood sugar and polyol pathway in diabetic albino rats", Plant Food Hum Nutr, (57) :41-52.

55. Suryanarayana, P., Saraswat M, Mrudula T, et al., (2005), "Curcumin and turmeric delay streptozotocininduced diabetic cataract in rats", Invest Ophthalmol Vis Sci, (46) :2092-2099.

56. Panahi, Y., Hosseini, M. S., Khalili, N., et al., (2016), "Effects of supplementation with curcumin on serum adipokine concentrations: $A$ randomized controlled trial", Nutrition, (32):1116-1122.

57. Lopresti, A. L., Maes, M., Meddens, M. J., et. al., (2015), "Curcumin and major depression: A randomised, double-blind, placebo-controlled trial investigating the potential of peripheral biomarkers to predict treatment response and antidepressant mechanisms of change", European Neuropsycho-pharmacology, (25) : 38-50.

58. Aggarwal, B. B., Kumar, A., Bharti, A. C., (2003), "Anticancer potential of curcumin: preclinical and clinical studies", Anticancer Res., 23(1A) :363-398.

59. Devasena, T., Rajasekaran, K. N., et al., (2003), "Anticarcinogenic effect of bis-1,7-(2-hydroxyphenyl)hepta-1,6-diene-3,5-dione a curcumin analog on DMHinduced colon cancer model', Pharmacol Res., (47) :133140.

60. Di, G. H., Li, H. C., Shen, Z. Z., Shao, Z. M., (2003), "Analysis of anti-proliferation of curcumin on human breast cancer cells and its mechanism", [in Chinese]. Zhonghua Yi Xue Za Zhi., (83) :1764-1768.

61. Dorai, T., Cao, Y. C., Dorai, B., Buttyan, R., Katz, A. E., (2001), "Therapeutic potential of curcumin in 
human prostate cancer. III. Curcumin inhibits proliferation, induces apoptosis, and inhibits angiogenesis of LNCaP prostate cancer cells in vivo", Prostate, (47) :293-303.

62. Azuine, M. A., Bhide, S. V., (1992), "Chemopreventive effect of turmeric against stomach and skin tumors induced by chemical carcinogens in Swiss mice", Nutr Cancer, (17) :77-83.

63. Moragoda, L., Jaszewski, R., Majumdar, A. P., (2001), "Curcumin induced modulation of cell cycle and apoptosis in gastric and colon cancer cells", Anticancer Res., 21(2A) :873-878.

64. Bruck, R., Ashkenazi, M., Weiss, S., et al., (2007), "Prevention of liver cirrhosis in rats by curcumin", Liver Int., (27) :373-383.

65. Kim, H. J., Yoo, H. S., Kim, J. C., et al., (2009), "Antiviral effect of Curcuma longa Linn extract against hepatitis B virus replication", J Ethnopharmacol., (124) :189-196.

66. Lau, C. B. S., Yue, G. G. L., et. al., (2010), "Immunostimulatory activities of polysaccharide extract isolated from Curcuma longa", International Journal of Biological Macromolecules, (47) : 342-347.

67. Rajagopal, M. H., Manjegowda, S. B, Serkada, C., Dharmeshab, S. M., (2018), "A modified pectic polysaccharide from turmeric (Curcuma longa) with antiulcer effects via anti-secretary, mucoprotective and IL-10 mediated anti-inflammatory mechanisms", Int J Biol Macromol. (118-Pt A) :864-880.

68. Harsha, M. R., Chandra-Prakash. S. V, Dharmesh. S. M., (2016), "Modified pectic polysaccharide from turmeric (Curcuma longa):A potent dietary component against gastric ulcer", Carbohydrate Polymers, (138) :143-155

69. Mohankumar, S., McFarlane, J. R., (2011), "An Aqueous Extract of Curcuma longa (Turmeric) Rhizomes Stimulates Insulin Release and Mimics Insulin Action on Tissues Involved in Glucose Homeostasis In Vitro", Phytother. Res., (25) : 396-401.

70. Chandrasekaran, C. V., Sundarajan, K., et al., (2013), "Immune-stimulatory and anti-inflammatory activities of Curcuma longa extract and its polysaccharide fraction”, Pharmacognosy Research, 5(2) :71-79.

71. Tomoda, M., et. al, (1992), "Characterization of a natural polysaccharide having activity on the reticuloedothelial system from the rhizomes of Curcuma longa”, Chem. Pharm. Bull., 40(1) :185-188.

72. Tomoda, M., et. al, (1990), "Characterization of polysaccharide having activity on the reticuloedothelial system from the rhizomes of Curcuma longa", Chem. Pharm. Bull., 38(2) :482-486.

73. Tomoda, M., Gonda, R., et. al., (1990b), “A reticulo-endothelial system activating glycan from the rhizomes of Curcuma longa", Phytochemistry, 29(4) :1083-1086.

74. Tomoda, M., Gonda, R., et. al, (1992b), "The core structure of ukonan $A$, a phagocytosis-activating polysaccharide from rhizome of Curcuma longa and immunological activities of degradation products", chem. pharm. Chem, 40(4) :990-993.
75. Tomoda, M., Gonda, R., et. al, (1993), "Arabinogalactan core structure and immunological activities of ukonan $\mathrm{C}$, an acidic polysaccharidefrom rhizomes of Curcuma longa", 16(3) :235-238.

76. Bhaumik, S., Jyothi, M. D., Khar, A., (2000), "Differential modulation of nitric oxide production by curcumin in host macrophages and NK cells", FEBS Lett., (483) :78-82.

77. Ridley, B. L., O’Neill, M. A., \& Mohnen, D., (2001), "Pectins: Structure, biosynthesis,and oligogalacturonide-related signaling", Phytochemistry, 57(6) :929-967.

78. Tomoda, M., Gonda, R., Shimizu, N., Kanari, M., Kimura, M., (1990c), "A reticuloendothelial system activating glycan from the rhizomes of Curcuma longa", Phytochemistry, (29) :1083-6.

79. Yue, G. G., Chan, B. C., Hon, P. M., Kennelly, E. J., et al., (2010), "Immuno-stimulatory activities of polysaccharide extract isolated from Curcuma longa", Int J Biol Macromol, (47) :342-7.

80. Deshpande, S. S., Ingle, A. D., Maru, G. B., (1998), "Chemopreventive efficacy of curcumin-free aqueous turmeric extract in 7,12-dimethylbenzo[a]anthracene-induced rat mammary tumorigenesis", Cancer Lett., 123(1) :35-40.

81. Yu, Z. F., Kong, L. D., Chen, Y., (2002), "Antidepressant activity of aqueous extracts of Curcuma longa in mice", J Ethnopharmacol, 83(1-2) :161-65.

82. Selvam, R., Subramanian, L., Gayathri, R., Angayarkanni, N., (1995), “The anti-oxidant activity of turmeric (Curcuma longa)”, J Ethnopharmacol, 47(2) :59-67.

83. Anbu-Jeba, S. J., Suraj, R., Rejitha, G., et. al, (2009), "In vitro antimicrobial evaluation of Zingiber officinale, Curcuma longa and Alpinia galanga extracts as natural food preservatives", Am J Food Technol, 4(5) :192-200.

84. Mishra, R. K., Singh, S. K., (2009), "Reversible antifertility effect of aqueous rhizome extract of Curcuma longa L. in male laboratory mice", Contraception, 79(6) :479-87.

85. Subramanian, L., Selvam, R., (1999), "Prevention of $\mathrm{CCl}_{4}$-induced hepatotoxicity by aqueous extract of turmeric", Nutr. Res., 19(3) :429-41.

86. Dharmesh, S. M. S., Jayaram, S., "Bioactive polysaccharide from turmeric (Curcuma longa) and process for preparation of same", COUNCIL SCI\& IND RES INDIA (Patent NO. IN200900314-11), (2010, August 27).

87. Illuri, R., Bethapudi, B., Anandakumar, S., et al., (2015), "Anti-inflammatory activity of polysaccharide fraction of Curcuma longa extract (NR-INF-02)", Antiinflamm. Antiallergy Agents Med. Chem., (14) :53-62.

88. Lau, C. B. S., Yue, G. G. L., et. al, (2010), "Immuno-stimulatory activities of polysaccharide extract isolated from Curcuma longa", International Journal of Biological Macromolecules, 47(3) :342-347.

89. Yegnanarayan, R., Saraf, A. P., Balwani, J. H., (1976), "Comparison of anti-inflammatory activity of various extracts of Curcuma longa (Linn.)., Indian J Med Res, (64) :601-8. 
90. Pan, M., Wu, J., Chi-Tang Ho, C., Badmaev, V., (2017), "Effects of water extract of Curcuma longa (L.) roots on immunity and telomerase function", Journal of Complementary and Integrative Medicine., 14(3), article no. 20150107.

91. Chandrasekaran, C.V., et. al, (2015), “AntiInflammatory Activity of Polysaccharide Fraction of Curcuma longa Extract (NR-INF-02)", AntiInflammatory \& Anti-Allergy Agents in Medicinal Chemistry, 14 :53-62.

92. Velusami, C. C., Bethapudi, B., et. al., (2017), "Bioactive Turmerosaccharides from Curcuma longa Extract (NR-INF-02): Potential Ameliorating Effect on Osteoarthritis Pain", Pharmacognosy Magazine, 13 (51) : 5623-27.

93. Velusami, C. C., Richard, E. J., Bethapudi, B., (2018), "Polar extract of Curcuma longa protects cartilage homeostasis: possible mechanism of action", Inflammopharmacology, 26(5) :1233-1243.

94. Madhu, K., Chanda, K., Saji, M.J., (2013), "Safety and efficacy of Curcuma longa extract in the treatment of painful knee osteoarthritis: A randomized placebocontrolled trial", Inflammopharmacology, (21) :129-136.

95. Wandel, S., Juni, P., Tendal, B., et. al., (2010), "Effects of glucosamine, chondroitin, or placebo in patients with osteoarthritis of hip or knee: network metaanalysis", Br. Med. Assoc., (341) :c4675.

96. Chanda, K., Leena, A., Lohit, K., et. al., (2012), “ $A$ randomized comparative study of safety and efficacy of immediate release glucosamine $\mathrm{HCL}$ and glucosamine HCL sustained release formulation in the treatment of knee osteoarthritis: A proof of concept study", J. Pharmacol. Pharmacotherapeut., (3) :48-54.

97. Madan, B., Gade, W. N., Ghosh, B., (2001), "Curcuma longa activates $\mathrm{NF}-\mathrm{kB}$ and promotes adhesion of neutrophils to human umbilical vein endothelial cells", Journal of Ethnopharmacology, (75) :25-32.

98. Velusami, C. C., Bethapudi, B., et. al., (2017), "Bioactive Turmerosaccharides from Curcuma longa Extract (NR-INF-02): Potential Ameliorating Effect on Osteoarthritis Pain", Pharmacognosy Magazine, 13(51) :5623-27.

99. Al-Lahham, S., Sawafta A. et. al, (2017), "Polar Curcuma longa extract inhibits leptin release by adipose tissue derived from overweight and obese people", European Journal of Inflammation, 15(3) :244-249.

100. Velusami, C. C., Boddapati, S. R., et. al., (2013), "Safety Evaluation of Turmeric Polysaccharide Extract: Assessment of Mutagenicity and Acute Oral Toxicity", BioMed Research International, (2013), Article ID $158348,:$ 1-10.

101. Shankar, T. N. B., Shantha, N. V., Ramesh, H. P., (1980), “Toxicity studies on turmeric (Curcuma longa): acute toxicity studies in rats, guinea pigs \& monkeys," Indian Journal of Experimental Biology, 18(1) : 73-75.

102. Deshpande, S. S., Ingle, A. D., Maru, G. B., (1997), “Inhibitory effects of curcumin-free aqueous turmeric extract on benzo(a)pyrene induced forestomach papillomas in mice”, Cancer Lett. (118) :79-85.
103. Azuine, M. A., Kayal, J. J., Bhide, S. V., (1992), "Protective role of aqueous turmeric extract against mutagenicity of direct acting carcinogens as well as benzo(a)pyrene-induced gcnotoxicity and carcinogenicity”, J. Cancer Res. Clin. Oncol., (118) :447452. 